\title{
Propagação clonal rápida de amoreira preta 'Xingu' por miniestaquia
}

\author{
Rapid clonal propagation of 'Xingu' blackberry by mini-cuttings \\ Propagación clonal rápida de la mora 'Xingu' mediante mini esquejes
}

Recebido: 16/12/2020 | Revisado: 24/12/2020 | Aceito: 04/01/2021 | Publicado: 06/01/2021

\author{
Felipe Asprino Joaquini \\ ORCID: https://orcid.org/0000-0001-6216-5730 \\ Universidade Federal do Paraná, Brasil \\ E-mail: felipeasprino@gmail.com \\ Luiz Antonio Biasi \\ ORCID: https://orcid.org/0000-0002-3479-8925 \\ Universidade Federal do Paraná, Brasil \\ E-mail: biasi@ufpr.br \\ Mauro Brasil Dias Tofanelli \\ ORCID: https://orcid.org/0000-0002-1831-3326 \\ Universidade Federal do Paraná, Brasil \\ E-mail: mbrasildt@ufpr.br
}

\begin{abstract}
Resumo
A miniestaquia tem sido utilizada para diversas espécies lenhosas, apresentando maior eficiência do que a propagação por estaquia convencional, devido seu elevado rendimento de material propagativo e maior porcentagem de enraizamento das miniestacas. Este trabalho foi realizado para avaliar a eficiência da técnica de miniestaquia para amoreira preta 'Xingu'. O minijardim foi instalado em vasos a partir de estacas de raízes. Foram realizadas 4 coletas de miniestacas entre 24/10/2019 a 12/03/2020, as quais receberam os seguintes tratamentos: estacas apicais sem AIB, estacas medianas sem AIB, estacas medianas $+500 \mathrm{mg} \mathrm{L}^{-1}$ de AIB e estacas medianas $+1000 \mathrm{mg} \mathrm{L}^{-1} \mathrm{de}$ AIB. A miniestaquia foi realizada em câmara de nebulização e avaliada após 35 dias. O rendimento de miniestacas aumento da primeira até a terceira coleta, diminuindo na quarta coleta, quando as plantas iniciaram a entrada em dormência. A quantidade acumulada de miniestacas de amoreira preta 'Xingu' atingiu $916 \mathrm{~m}^{-2}$, num período inferir a 5 meses. A porcentagem de estacas enraizadas foi em geral acima de $80 \%$, ocorrendo diferença significativa entre os tratamentos apenas na segunda coleta. As estacas medianas apresentaram maior número e comprimento de raízes do que as apicais e a aplicação de AIB apresentou pouco e variado efeito sobre o enraizamento. Conclui-se que a miniestaquia é uma técnica eficiente para a propagação rápida e em larga escala da amoreira preta 'Xingu' e pode ser realizada com todas as porções das brotações das minicepas sem necessidade de aplicação de auxina.
\end{abstract}

Palavras-chave: Rubus sp.; Propagação vegetativa; Estaquia; Auxina.

\begin{abstract}
Mini-cuttings have been used for several woody species, showing greater efficiency than propagation by conventional cuttings, due to their high yield of propagating material and higher percentage of rooting of mini-cuttings. This work was carried out to evaluate the efficiency of the mini-cutting technique for blackberry 'Xingu'. The mini-garden was installed in pots from root cuttings. Four mini-cutting collections were carried out from 10/24/2019 to 12/03/2020, that received the following treatments: apical cuttings without IBA, median cuttings without IBA, median cuttings + $500 \mathrm{mg} \mathrm{L}^{-1}$ of IBA and median cuttings $+1000 \mathrm{mg} \mathrm{L}^{-1}$ of IBA. Mini-cutting was performed in a nebulization chamber and evaluated after 35 days. The yield of mini-cuttings increased from the first to the third collection, decreasing in the fourth collection, when the plants started to go into dormancy. The accumulated quantity of blackberry minicuttings 'Xingu' reached $916 \mathrm{~m}^{-2}$, in a period less than 5 months. The percentage of rooted cuttings was generally above $80 \%$, with a significant difference among treatments only in the second collection. The median cuttings showed a greater number and length of roots than the apical ones and the application of IBA had little and varied effect on rooting. It is concluded that the mini-cutting is an efficient technique for the rapid and large-scale propagation of the blackberry 'Xingu' and can be carried out with all portions of the sprouts of the mini-tumps without the need for auxin. Keywords: Rubus sp.; Vegetative propagation; Cutting; Auxin.
\end{abstract}

\section{Resumen}

Se han utilizado mini-esquejes para varias especies leñosas, mostrando mayor eficiencia que la propagación por esquejes convencionales, debido a su alto rendimiento de material de propagación y mayor porcentaje de enraizamiento de los mini-esquejes. Este trabajo se llevó a cabo para evaluar la eficacia de la técnica de minicorte de mora 'Xingu'. El mini jardín se instaló en macetas a partir de esquejes de raíces. Entre el 24/10/2019 y el 03/12/2020, que recibió los siguientes tratamientos: esquejes apicales sin IBA, esquejes medianos sin IBA, esquejes medianos + $500 \mathrm{mg} \mathrm{L}^{-1}$ de IBA y esquejes medianos $+1000 \mathrm{mg} \mathrm{L}^{-1}$ de IBA. Se realizó un mini-corte en una cámara de 
nebulización y se evaluó después de 35 días. El rendimiento de mini-esquejes aumentó de la primera a la tercera colección, disminuyendo en la cuarta colección, cuando las plantas comenzaron a entrar en letargo. La cantidad acumulada de minicortes de mora 'Xingu' alcanzó los $916 \mathrm{~m}^{-2}$, en un período inferior a 5 meses. El porcentaje de esquejes enraizados fue generalmente superior al $80 \%$, con una diferencia significativa entre tratamientos solo en la segunda colección. Las estacas medianas mostraron mayor número y longitud de raíces que las apicales y la aplicación de IBA tuvo poco y variado efecto sobre el enraizamiento. Se concluye que el minicorte es una técnica eficaz para la propagación rápida y a gran escala de la mora 'Xingu' y se puede realizar con todas las porciones de los brotes de las minicrafts sin necesidad de aplicación de auxinas.

Palabras clave: Rubus sp.; Propagación vegetativa; Corte; Auxina.

\section{Introdução}

A amoreira preta (Rubus sp.) é uma pequena fruta que tem despertado o interesse de cultivo pelos fruticultores, devido suas características de alta produtividade, facilidade de manejo e opções de comercialização para o mercado de frutas frescas ou processadas (Antunes, et al., 2014). Em pomares bem manejados e com irrigação, altas produtividades são obtidas, como verificado com a 'Tupy' cultivada na Lapa-PR, que produziu 20,1 e 26,8 t ha ${ }^{-1}$ nas safras de 2012/13 e 2013/14 (Croge, et al., 2019a). O cultivo de amoreira preta é uma opção para a diversificação de espécies frutíferas em pequenas propriedades, que adotam com mais frequência sistemas orgânicos de produção (Soler \& Biasi, 2020).

O melhoramento da amoreira preta, conduzido pela Embrapa Clima Temperado, tem contribuído muito para o desenvolvimento da cultura com o lançamento de cultivares mais produtivas e adaptadas as condições climáticas brasileiras, sendo recentemente lançada a cultivar Xingu (Raseira, et al., 2018), que apresenta produção superior a cultivar Tupy, que foi considerada a cultivar de amoreira preta mais importante do mundo em 2010 (Volk, et al., 2013).

A demanda de mudas de novas cultivares é elevada após o lançamento e os viveiros precisam adotar novas e mais eficientes técnicas de propagação rápida e em grande quantidade. A amoreira preta pode ser propagada pela estaquia tanto caulinar como radicular (Hussain, et al., 2017). A estaquia caulinar a partir de estacas lenhosas, apresenta mais dificuldade para a produção de mudas, devido ao baixo enraizamento deste tipo de estaca (Vendrusculo, et al., 2018). A estaquia lenhosa foi considerada uma técnica ineficiente para a propagação de amoreira preta após a realização de diversos experimentos, mesmo com uso de auxinas nas cultivares americanas Apache, Arapaho, Kiowa, Osage, Ouachita, Siskiyou e Triple Crown (Debner, et al., 2019). A estaquia radicular apresenta melhor eficiência, com taxas mais elevadas de enraizamento e brotação (Campagnolo \& Pio, 2012). Entretanto, a obtenção de estacas radiculares é mais trabalhosa e causa grandes danos nas plantas matrizes. Outra forma de produção de mudas é a micropropagação, que apresenta elevada eficiência, conforme já obtido com a cultivar Xingu, que apresentou alta taxa de multiplicação em meio de cultura MS com $5 \mu \mathrm{M}$ de BAP e facilidade de enraizamento ex vitro sem uso de auxinas (Schiehl, et al., 2020). Mas são poucos os viveiros que dispõem de um laboratório de cultura de tecidos para realizar esta técnica. Desta forma se faz necessário o desenvolvimento de técnicas mais eficientes de propagação vegetativa para a produção rápida de mudas de amoreira preta.

A miniestaquia é uma técnica que vem demonstrando excelentes resultados para espécies que apresentam dificuldades de enraizamento de estacas caulinares (Dias, et al., 2012a). Esta técnica foi desenvolvida para espécies lenhosas de uso florestal, sendo muito utilizada para o eucalipto (Eucalyptus spp.) (Wendling, et al., 2000; Xavier, et al., 2001; Brondani, et al., 2014), mas com bons resultados comprovados para outras espécies lenhosas, como o pau-rosa (Aniba Rosaeodora) (Menezes, et al., 2018), Acacia mearsii (Engel, et al., 2017), ipê-roxo (Handroanthus heptaphyllus) (Oliveira, et al., 2016), vassourão-branco (Piptocarpha angustifolia) (Ferriani, et al., 2011), guanandi (Calophyllum brasiliensis) (Silva, et al., 2010), leiteiro (Sapium glandulatum) (Ferreira, et al., 2010) e também para espécies frutíferas como o araçazeiro, goiabeira (Altoé, et al., 2011), pitangueira (Eugenia uniflora) (Peña, et al., 2015) e mirtileiro (Vaccinium sp.) (Koyama, et al., 2018).

A miniestaquia apresenta algumas vantagens em relação à estaquia para a produção de mudas, como a menor área necessária para a formação do minijardim clonal em relação a plantas matrizes mantidas no campo, redução dos custos com 
transporte e coleta das brotações, maior controle do minijardim em relação a pragas e doenças, maior produção de miniestacas por unidade de área e maior eficiência na propagação de espécies de difícil enraizamento (Xavier, et al., 2003; Xavier, et al., 2009; Dias, et al., 2012a; Menezes, et al., 2018).

A técnica consiste inicialmente na instalação de um minijardim de preferência clonal, para manter inalteradas as características de interesse do clone ou da cultivar que se deseja propagar. As plantas são mantidas em recipientes contendo substrato preparado para proporcionar um bom desenvolvimento do sistema radicial. A necessidade hídrica e a nutricional também são controladas para permitir o melhor crescimento das plantas. Após a formação do minijardim, as plantas são podadas em intervalos regulares fornecendo material de propagação, que pelo seu reduzido tamanho são chamadas de miniestacas. Desta forma, sempre são utilizadas brotações jovens, que apresentam melhor capacidade para a formação adventícia de raízes (Altoé, et al., 2011; Dias, et al., 2012a). Na parte apical das brotações com intensa atividade de crescimento são formadas as auxinas, que são transportadas pelo floema em sentido descendente e após o corte da brotação acumulam na base da minietaca, induzindo a rizogênese. Em várias espécies a aplicação exógena de auxina não é necessária para a formação de raízes nas miniestacas, como verificado para pau-rosa (Aniba rosaeodora) (Menezes, et al., 2018), angico vermelho (Anadenathera macrocarpa) (Dias, et al., 2012b), ipê-roxo (Handroanthus heptaphyllus) (Oliveira, et al., 2016), leiteiro (Sapium glandulatum) (Ferreira, et al., 2010) e guanandi (Calophyllum brasiliensis) (Silva, et al., 2010).

Considerando que a miniestaquia pode elevar a taxa de enraizamento de estacas de amoreira preta, da mesma forma como já foi comprovado para outras espécies lenhosas, este trabalho foi realizado com o objetivo de avaliar a eficiência da técnica de miniestaquia para amoreira preta 'Xingu'.

\section{Metodologia}

As plantas matrizes de amoreira-preta 'Xingu' utilizadas neste experimento foram micropropagadas a partir de culturas já estabelecidas in vitro cedidas pela Embrapa Clima Temperado. Após a multiplicação in vitro, as plantas foram aclimatizadas e cultivadas em vasos em casa de vegetação do Departamento de Fitotecnia e Fitossanidade da Universidade Federal do Paraná, em Curitiba-PR.

No dia 05 de julho de 2019, as plantas matrizes foram retiradas dos vasos para a produção das estacas radiculares e instalação no minijardim clonal. As raízes com diâmetro entre 0,5 a $1 \mathrm{~cm}$ foram cortadas com $5 \mathrm{~cm}$ de comprimento. As estacas radiculares foram colocadas em vasos com capacidade de $5 \mathrm{~L}$, sendo mantidas na posição horizontal e cobertas com $3 \mathrm{~cm}$ de substrato. O substrato utilizado foi uma mistura de substrato comercial Mecplant® e vermiculita em uma proporção de 2:1 e para adubação inicial foi aplicado adubo de liberação lenta (Basacote ${ }^{\circledR}$ Plus $3 \mathrm{M}$ 16-8-12) na concentração de $3 \mathrm{~g} \mathrm{~L}^{-1}$ de substrato.

O minijardim clonal foi instalado com 20 vasos contendo 5 estacas radiculares por vaso. Os vasos ficaram sobre uma bancada ocupando um espaço de $1,7 \mathrm{~m}^{-2}$. O minijardim foi regado de acordo com a necessidade hídrica e recebeu adubação com $3 g$ de Basacote ${ }^{\circledR}$ por vaso após cada coleta de estacas.

As miniestacas foram padronizadas com tamanho de 5 a 6 centímetros de comprimento, contendo uma gema na parte apical e uma folha com apenas dois folíolos, procurando manter uma área foliar semelhante entre as estacas. As estacas apicais foram preparadas com a porção apical das brotações contendo uma ou duas folhas novas ainda não totalmente expandidas.

A metodologia de investigação adotada neste trabalho foi da pesquisa exploratória utilizando o método quantitativo (Pereira, et al., 2018). Para cada coleta foi instalado um experimento com delineamento inteiramente ao acaso, contendo 4 tratamentos, 4 repetições e 10 estacas por parcela. Os tratamentos foram: estacas apicais sem AIB, estacas medianas sem AIB, estacas medianas $+500 \mathrm{mg} \mathrm{L}^{-1}$ de AIB e estacas medianas $+1000 \mathrm{mg} \mathrm{L}^{-1}$ de AIB. O tratamento com AIB foi realizado pela imersão da base das estacas durante 5 segundos na solução de AIB diluído em etanol 50\%. As estacas foram plantadas em 
tubetes plásticos de $140 \mathrm{~cm}^{3}$ contendo apenas vermiculita fina e mantidos em câmara de nebulização. A frequência de rega foi de 30 segundos a cada 30 minutos durante o período das 08:00 as 19:00 e de 30 segundos a cada 3 horas durante o período das 19:00 às 08:00.

Foram realizadas 4 coletas nos dias 24/10/2019, 03/12/2019, 22/01/2020 e 12/03/2020, com intervalo de 40 dias entre a primeira e a segunda coleta e 50 dias entre as demais. As avaliações foram realizadas nos dias 28/11/2019, 08/01/2020, 27/02/2020 e 16/04/2020, com 35 ou 36 dias após a instalação.

As temperaturas que ocorreram durante o período de realização do experimento foram obtidas da Estação Meteorológica do Instituto Nacional de Meteorologia (INMET), localizada em Curitiba-PR (Figura 1).

Em cada coleta foi avaliado o número de estacas produzidas pelo minijardim clonal. As avaliações da estaquia foram realizadas pelos seguintes parâmetros: número de estacas enraizadas, estacas vivas sem raízes, estacas mortas, estacas brotadas e estacas que mantiveram a folha, número de raízes por estacas e comprimento da maior raiz. Foram consideradas estacas enraizadas, aquelas que possuíam pelo menos uma raiz maior do que $1 \mathrm{~mm}$. A retenção foliar foi calculada pela percentagem de estacas que possuíam a folha deixada no preparo das mesmas. Os dados foram analisados pela análise de variância e as médias comparadas pelo teste de Tukey a 5\% de probabilidade pelo programa SISVAR (Ferreira, 2011).

Figura 1. Temperatura diária máxima, média e mínima registrada em Curitiba-PR, durante o período de 01 de outubro de 2019 a 30 de abril de 2020 .

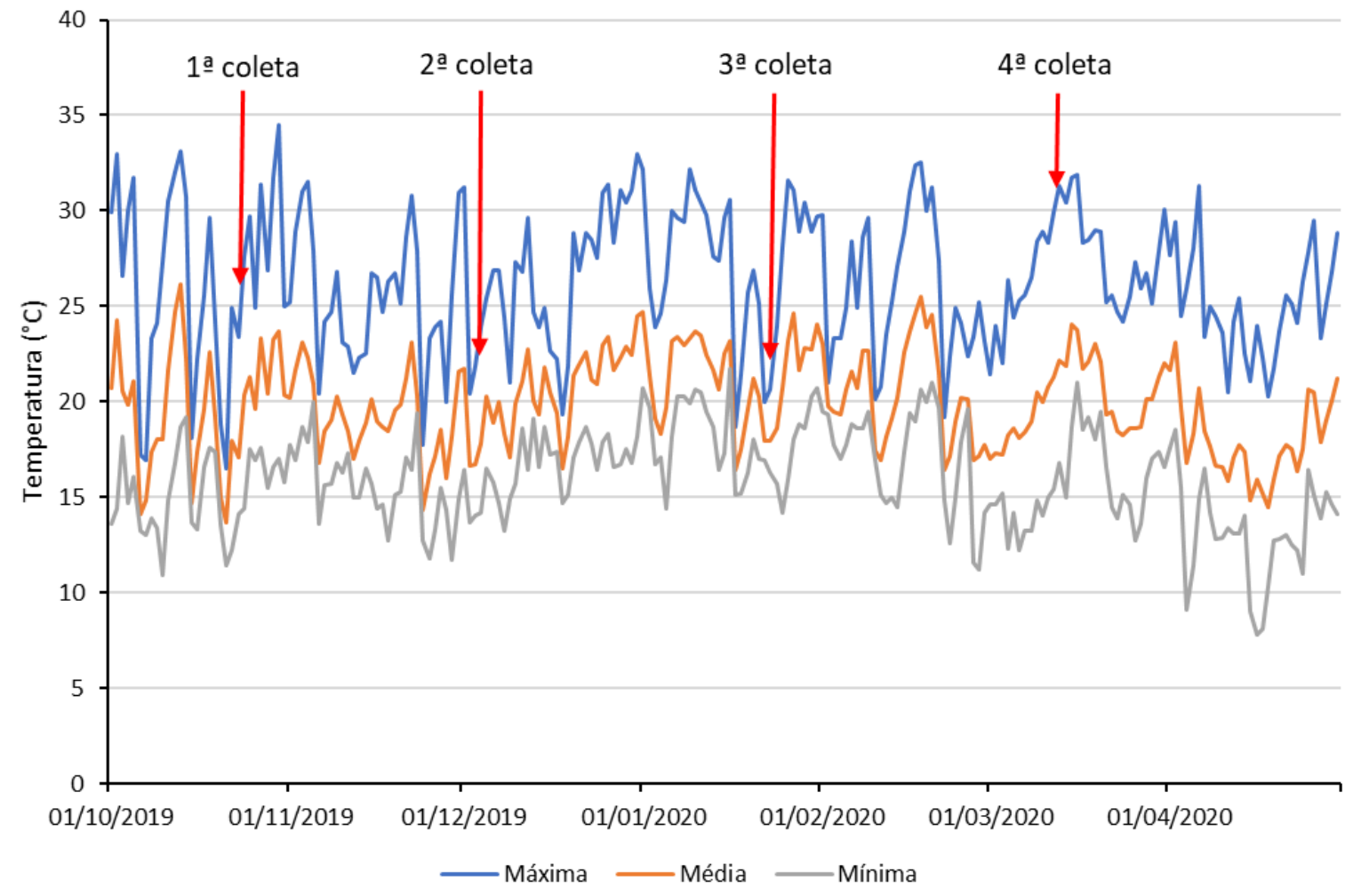

Fonte: Instituto Nacional de Meteorologia - INMET.

Na Figura 1 pode-se observar a variação nas temperaturas máxima, média e mínima que ocorreram em Curitiba-PR nos dias de cada coleta e durante o período de cada miniestaquia. 


\section{Resultados e Discussão}

O minijardim clonal apresentou elevada taxa de sobrevivência das minicepas, não ocorrendo a morte de plantas matrizes durante a condução do experimento. Foram realizadas quatro coletas de miniestacas durante o período de 24 de outubro de 2019 a 12 de março de 2020. O rendimento do minijardim aumentou da primeira para a terceira coleta e diminuiu na quarta coleta (Figura 2A). Na primeira coleta foram obtidas 112 miniestacas $\mathrm{m}^{-2}$, na segunda 220 miniestacas $\mathrm{m}^{-2}$, na terceira 365 miniestacas $\mathrm{m}^{-2} \mathrm{e}$ na quarta 219 miniestacas $\mathrm{m}^{-2}$.

Figura 2. Número de estacas produzidas (A) e estimativa de estacas enraizadas (B) por coleta e acumuladas oriundas de minijardim clonal de amoreira-preta 'Xingu'.

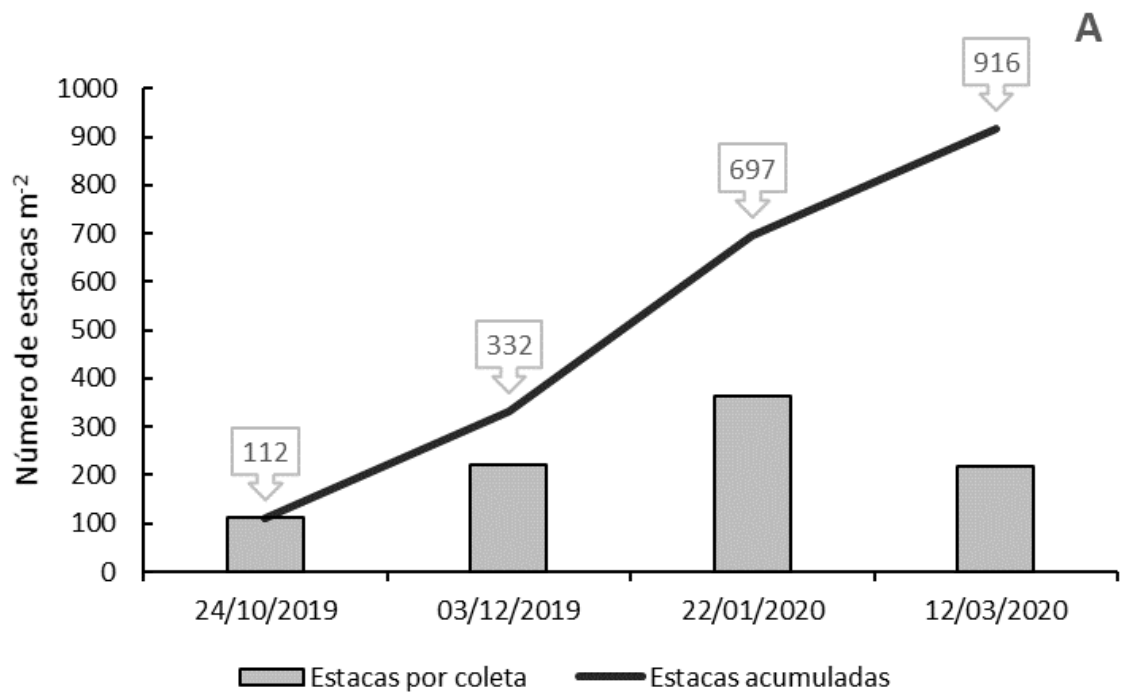

B

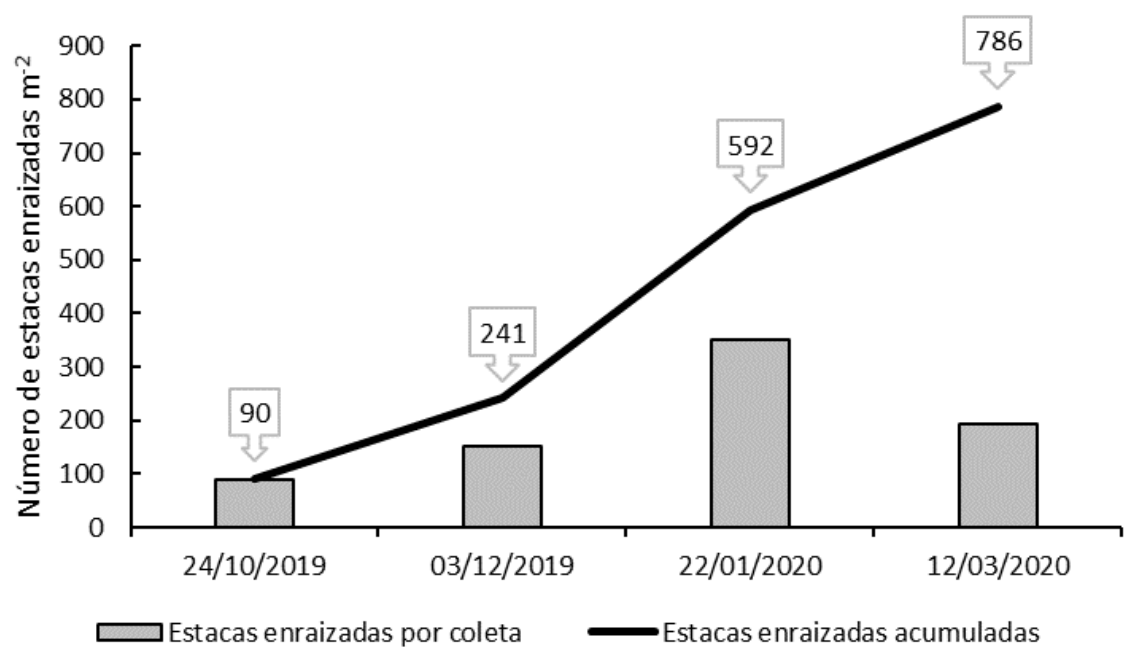

Fonte: Autores.

A redução do rendimento de estacas na quarta coleta realizada em março, ocorreu pelo menor crescimento das brotações nesta época. Isto também foi verificado em outras espécies, mesmo sendo perenifólias, onde as coletas realizadas no outono e inverno, apresentaram menor rendimento de miniestacas em comparação com as estações mais quentes do ano 
(Ferreira, et al., 2010; Peña, et al., 2015). A amoreira preta é uma espécie de clima temperado que apresenta um período de dormência durante os meses mais frio do ano. Desta forma, as minicepas apresentaram redução da atividade de crescimento vegetativo após a terceira coleta e após a quarta coleta não houve mais crescimento de brotações que permitisse novas coletas. A partir de 22/02/2020 houve redução das temperaturas médias, sendo verificado uma média de $18,5{ }^{\circ} \mathrm{C}$ até a data da quarta coleta, enquanto no período entre a segunda e terceira coleta, a temperatura média foi de $20,5^{\circ} \mathrm{C}$ (Figura 1). Após a quarta coleta, o minijardim entrou em dormência e permaneceu assim até setembro de 2020, quando ocorreu a brotações de gemas que originaram ramos frutíferos. Os ramos frutíferos de amoreira preta são curtos, com poucas folhas e vários frutos, não sen do possível sua utilização para a propagação vegetativa. Para a formação de novos ramos vegetativos, o minijardim precisou ser podado de forma mais drástica em outubro. Brotações vegetativas se formaram e o minijardim poderia iniciar um novo ciclo de coleta de estacas.

$\mathrm{Na}$ miniestaquia de Sapium glandulatum foram obtidas 526 minestacas $\mathrm{m}^{-2}$, como média de 4 coletas, mas as minicepas foram cultivadas com grande adensamento, pois foram plantadas em tubetes de $205 \mathrm{~cm}^{3}$ (Ferreira, et al., 2010). Em minijardim de origem seminal de araçazeiro (Psidium guineense e Psidium cattleyanum) e goiabeira (Psidium guajava), cultivados em tubetes de $280 \mathrm{~cm}^{3}$, houve aumento do número de brotações emitidas pelas minicepas até 166 dias após o primeiro desponte e as quantidades mais altas de miniestacas obtidas por minicepa foram 3,99, 4,83 e 3,62, respectivamente. Para estas espécies foi possível realizar 7 coletas de miniestacas em 347 dias (Altoé, et al., 2011). Em minijardim também de origem seminal de pitangueira (Eugenia uniflora), instalado em tubetes de $240 \mathrm{~cm}^{3}$, foram realizadas 8 coletas no período de um ano, sendo obtidas em média 616 miniestacas por coleta (Peña, et al., 2015). As espécies arbóreas apresentam maior adaptação para o cultivo em tubetes, permitindo grande adensamento do minijardim e maior produtividade de miniestacas. Além dos tubetes, a instalação do minijardim em sistema semi-hidropônico tem apresentado bons resultados de rendimento para espécies lenhosas (Cunha, et al., 2008; Ferriani, et al., 2011; Dias, et al., 2012a). A amoreira-preta, devido ao seu crescimento arbustivo e grande desenvolvimento das raízes, não se adapta a recipientes tão pequenos. Mas, mesmo em recipientes maiores, a quantidade acumulada de miniestacas de amoreira preta 'Xingu' atingiu $916 \mathrm{~m}^{-2}$, num período inferir a 5 meses. Este elevado rendimento não seria obtido $\mathrm{em} 1 \mathrm{~m}^{2}$ de plantas normalmente cultivadas no campo.

Considerando as porcentagens de enraizamento obtidas em cada coleta, foi estimada a quantidade de miniestacas enraizadas do minijardim (Figura 2B). Na primeira coleta foram estimadas 90 miniestacas enraizadas $\mathrm{m}^{-2}$, na segunda 151 miniestacas enraizadas $\mathrm{m}^{-2}$, na terceira 351 miniestacas enraizadas $\mathrm{m}^{-2}$ e na quarta 194 miniestacas enraizadas $\mathrm{m}^{-2}$. $\mathrm{O}$ total acumulado de miniestacas enraizadas foi estimando em $786 \mathrm{~m}^{-2}$, que teriam condições de originar mudas de amoreira-preta.

As miniestacas apresentaram alta porcentagem de enraizamento, chegando a atingir 97,5\% e apenas houve diferença significativa entre os tratamentos na segunda coleta, quando as estacas apicais foram inferiores as medianas (Tabela 1). Na segunda coleta ocorreu elevada mortalidade $(62,5 \%)$ e baixa retenção foliar (37\%) nas estacas apicais, que são muito tenras e suscetíveis a desidratação. As médias das temperaturas, durante os períodos que as miniestacas permaneceram em avaliação, não variaram muito, mas na segunda coleta houve um longo período de temperaturas altas, de 20/12/2019 a 01/01/2020, que pode ter prejudicado a sobrevivência das miniestacas (Figura 1). Não houve efeito significativo da aplicação de AIB nas estacas medianas, fato também verificado com outras cultivares de amoreira preta (Yamamoto, et al., 2013; Bicca, et al., 2020). Nas demais épocas de coleta não houve diferença significativa entre os tratamentos, ocorrendo baixa mortalidade e elevada retenção foliar. Também não houve diferença significativa entre os tratamentos para a porcentagem de estacas vivas sem raízes e estacas brotadas nas quatro épocas de coleta (Tabela 1).

As taxas de enraizamento obtidas com a miniestaquia foram bem superiores as encontradas com estacas lenhosas da cultivar Tupy, que atingiu apenas 61,5\% (Vendruscolo, et al., 2018). A presença de folhas nas estacas auxilia no enraizamento, conforme verificado com a 'Tupy', cuja porcentagem de enraizamento subiu de $25 \%$ em estacas sem folhas, para $70,83 \%$ em 
estacas com folhas (Vignolo, et al., 2014). Estacas herbáceas da cultivar Xavante apresentaram melhor enraizamento, com taxas superiores a $80 \%$ sem diferença entre as estacas tratadas com $1000 \mathrm{mg} \mathrm{L}^{-1}$ de AIB ou não tratadas (Yamamoto, et al., 2013). Para a mesma cultivar de amoreira-preta, Bicca, et al. (2020) também verificaram que o AIB não foi necessário para estimular o enraizamento, pois ocasionou uma redução na porcentagem de miniestacas enraizadas.

As estacas apicais apresentaram menor número de raízes do que as estacas medianas em 3 datas de coletas. Apenas na terceira coleta não houve diferença significativa entre os tratamentos. As estacas tratadas com $1000 \mathrm{mg} \mathrm{L}^{-1} \mathrm{de} \mathrm{AIB}$ apresentaram número superior de raízes do que as não tratadas, na primeira e na quarta coleta. Já as tratadas com 500 mg $\mathrm{L}^{-1}$ de AIB não diferiram das não tratadas em todas as coletas. De uma forma geral, o número de raízes formadas nas miniestacas foi elevado, chegando a atingir 29,9 raízes nas miniestacas tratadas com $1000 \mathrm{mg} \mathrm{L}^{-1}$ de AIB na quarta coleta (Tabela 1). Na estaquia lenhosa das cultivares Xavante, Tupy e Guarani, foram obtidas apenas 5,04, 2,74 e 1,31 raízes por estaca (Vignolo, et al., 2014).

Tabela 1. Porcentagem de estacas enraizadas, vivas sem raízes, mortas, brotadas e com retenção foliar, número e comprimento de raízes de miniestacas de amoreira-preta 'Xingu'.

\begin{tabular}{|c|c|c|c|c|c|c|c|}
\hline Tratamentos & $\begin{array}{c}\text { Estacas } \\
\text { enraizadas } \\
(\%)\end{array}$ & $\begin{array}{c}\text { Estacas } \\
\text { vivas sem } \\
\text { raízes }(\%)\end{array}$ & $\begin{array}{c}\text { Estacas } \\
\text { mortas } \\
(\%)\end{array}$ & $\begin{array}{c}\text { Estacas } \\
\text { brotadas } \\
(\%)\end{array}$ & $\begin{array}{l}\text { Retenção } \\
\text { foliar (\%) }\end{array}$ & $\begin{array}{l}\text { Número de } \\
\text { raízes por } \\
\text { estacas }\end{array}$ & $\begin{array}{l}\text { Comprimento } \\
\text { da maior raiz } \\
(\mathrm{cm})\end{array}$ \\
\hline & \multicolumn{7}{|c|}{$1^{\mathrm{a}}$ coleta } \\
\hline $\begin{array}{l}\text { Apicais sem } \\
\text { AIB }\end{array}$ & $82,5^{\mathrm{ns}}$ & $0,0^{\mathrm{ns}^{*}}$ & $17,5^{\mathrm{ns} *}$ & $82,5^{\mathrm{ns}}$ & $82,5^{\mathrm{ns}}$ & $12,3 \mathrm{~b}$ & $7,5 \mathrm{ab}$ \\
\hline $\begin{array}{l}\text { Medianas sem } \\
\text { AIB }\end{array}$ & 67,5 & 10,0 & 22,5 & 65,0 & 77,5 & $12,7 \mathrm{~b}$ & $6,8 \mathrm{~b}$ \\
\hline $\begin{array}{l}\text { Medianas + } 500 \\
\mathrm{mg} \mathrm{L}^{-1} \text { AIB }\end{array}$ & 80,0 & 10,0 & 10,0 & 60,0 & 90,0 & $14,5 \mathrm{ab}$ & $7,4 a b$ \\
\hline $\begin{array}{l}\text { Medianas + } \\
1000 \mathrm{mg} \mathrm{L}^{-1} \mathrm{AIB}\end{array}$ & 95,0 & 0,0 & 5,0 & 75,0 & 95,0 & $19,6 \mathrm{a}$ & $9,5 \mathrm{a}$ \\
\hline \multirow[t]{2}{*}{ C.V. (\%) } & 17,59 & 68,18 & 43,99 & 20,33 & 12,74 & 21,58 & 14,51 \\
\hline & \multicolumn{7}{|c|}{$2^{a}$ coleta } \\
\hline $\begin{array}{l}\text { Apicais sem } \\
\text { AIB }\end{array}$ & $15,0 \mathrm{~b}$ & $22,5^{\mathrm{ns} *}$ & $62,5 \mathrm{a}^{*}$ & $27,5^{\mathrm{ns} *}$ & $37,5 \mathrm{~b}$ & $2,4 \mathrm{~b}$ & $3,8 \mathrm{~b}$ \\
\hline $\begin{array}{l}\text { Medianas sem } \\
\text { AIB }\end{array}$ & $82,5 \mathrm{a}$ & 12,5 & $5,0 \mathrm{~b}$ & 65,0 & $95,0 \mathrm{a}$ & $11,1 \mathrm{a}$ & $8,8 \mathrm{a}$ \\
\hline $\begin{array}{l}\text { Medianas + } 500 \\
\mathrm{mg} \mathrm{L}^{-1} \text { AIB }\end{array}$ & $80,0 \mathrm{a}$ & 10,0 & $10,0 \mathrm{~b}$ & 30,0 & $82,5 \mathrm{a}$ & $15,7 \mathrm{a}$ & $10,2 \mathrm{a}$ \\
\hline $\begin{array}{l}\text { Medianas + } \\
1000 \mathrm{mg} \mathrm{L}^{-1} \mathrm{AIB}\end{array}$ & $85,0 \mathrm{a}$ & 12,5 & $2,5 \mathrm{~b}$ & 45,0 & $97,5 \mathrm{a}$ & $15,3 \mathrm{a}$ & $9,3 \mathrm{a}$ \\
\hline \multirow[t]{2}{*}{ C.V. $(\%)$} & 22,75 & 42,40 & 39,27 & 22,56 & 15,35 & 30,97 & 28,81 \\
\hline & \multicolumn{7}{|c|}{$3^{a}$ coleta } \\
\hline $\begin{array}{l}\text { Apicais sem } \\
\text { AIB }\end{array}$ & $95,0^{\mathrm{ns}}$ & $0,0^{\mathrm{ns} *}$ & $5,0^{\mathrm{ns}^{*}}$ & $72,5^{\mathrm{ns}}$ & $95,0^{\mathrm{ns}}$ & $13,1^{\mathrm{ns}}$ & $10,0 \mathrm{~b}$ \\
\hline $\begin{array}{l}\text { Medianas sem } \\
\text { AIB }\end{array}$ & 95,0 & 5,0 & 0,0 & 60,0 & 100,0 & 15,5 & $12,1 \mathrm{ab}$ \\
\hline $\begin{array}{l}\text { Medianas + } 500 \\
\mathrm{mg} \mathrm{L}^{-1} \mathrm{AIB}\end{array}$ & 97,5 & 2,5 & 0,0 & 65,0 & 100,0 & 17,8 & $13,3 \mathrm{a}$ \\
\hline $\begin{array}{l}\text { Medianas + } \\
1000 \mathrm{mg} \mathrm{L}^{-1} \mathrm{AIB}\end{array}$ & 97,5 & 2,5 & 0,0 & 70,0 & 100,0 & 17,7 & $11,3 \mathrm{ab}$ \\
\hline \multirow[t]{2}{*}{ C.V. $(\%)$} & 5,61 & 66,96 & 51,86 & 27,22 & 2,92 & 21,80 & 12,85 \\
\hline & \multicolumn{7}{|c|}{$4^{a}$ coleta } \\
\hline $\begin{array}{l}\text { Apicais sem } \\
\text { AIB }\end{array}$ & $82,5^{\mathrm{ns}}$ & $15,0^{\mathrm{ns} *}$ & $5,0^{n s^{*}}$ & $75,0^{\mathrm{ns}}$ & $95,0^{\mathrm{ns}}$ & $7,5 \mathrm{c}$ & $5,85 \mathrm{~b}$ \\
\hline $\begin{array}{l}\text { Medianas sem } \\
\text { AIB }\end{array}$ & 85,0 & 15,0 & 0,0 & 77,5 & 100,0 & $12,8 \mathrm{~b}$ & $8,4 \mathrm{a}$ \\
\hline $\begin{array}{l}\text { Medianas + } 500 \\
\mathrm{mg} \mathrm{L}^{-1} \text { AIB }\end{array}$ & 95,0 & 7,5 & 0,0 & 80,0 & 100,0 & $15,1 \mathrm{~b}$ & $9,6 \mathrm{a}$ \\
\hline $\begin{array}{l}\text { Medianas + } \\
1000 \mathrm{mg} \mathrm{L}^{-1} \mathrm{AIB}\end{array}$ & 95,0 & 0,0 & 2,5 & 75,0 & 97,5 & 29,9 a & $10,3 \mathrm{a}$ \\
\hline C.V. $(\%)$ & 17,01 & 73,90 & 61,68 & 25,68 & 3,89 & 11,37 & 14,45 \\
\hline
\end{tabular}


Médias seguidas pela mesma letra não diferem significativamente pelo teste de Tukey a 5\% de probabilidade.

*Dados originais transformados em raiz $(\mathrm{x}+1)$ para análise.

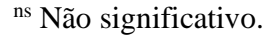

Fonte: Autores.

As estacas medianas apresentaram maior comprimento de raiz do que as apicais na segunda e na quarta coleta, não ocorrendo diferença entre as que foram tratadas com AIB e as não tratadas. Nas demais coletas houve maior variação entre os tratamentos, mas a tendência permaneceu a mesma. Na estaquia lenhosa das cultivares Guarani, Tupy e Xavante foi verificado que a presença das folhas nas estacas estimulou o crescimento das raízes, que atingiram em média $8,12 \mathrm{~cm}$, enquanto nas estacas sem folhas apenas 2,36cm (Vignolo, et al., 2014).

\section{Considerações Finais}

A miniestaquia é uma técnica eficiente para a propagação rápida e em larga escala da amoreira preta 'Xingu'. A miniestaquia desta espécie pode ser realizada com todas as porções das brotações das minicepas, tanto apicais como medianas, sem necessidade de aplicação de auxina.

Trabalhos futuros podem ser realizados, para avaliar com mais precisão as condições do ambiente durante o processo de miniestaquia, como temperatura, umidade e intensidade luminosa, visando o máximo enraizamento das miniestacas. Estudos sobre o manejo do minijardim clonal, com podas drásticas durante o período de dormência, podem viabilizar a continuidade de coletas de miniestacas por mais de um ciclo de crescimento.

\section{Referências}

Altoé, J. A., Marinho, C. S., Terra, M. I. C., \& Barroso, D. G. (2011). Propagação de araçazeiro e goiabeira via miniestaquia de material juvenil. Bragantia, 70(2), 312-318. https://www.redalyc.org/articulo.oa?id=90819310009

Antunes, L. E. C., Pereira, I. S., Picolotto, L., Vignoloto, G. K., \& Gonçalves, M. A. (2014). Produção de amoreira-preta no Brasil. Revista Brasileira de Fruticultura, 36(1), 100-111. 10.1590/0100-2945-450/13

Bicca, M. L., Silvia, J. P., Dias, C. S., Loy, F. S., Cruz, J. G., \& Silvia, F. L. (2020). Substratos e ácido indolbutírico no enraizamento de miniestacas de amoreira-preta 'Xavante' coletadas em duas épocas do ano. Research, Society and Development, 9(12), e13591210834. doi:10.33448/rsd-v9i12.10834

Brondani, G. E., Baccarin, F. J. B., Bergonci, T., Gonçalves, A. N., \& Almeida, M. (2014). Miniestaquia de Eucalyptus benthamii: efeito do genótipo, AIB, zinco, boro e coletas de brotações. Cerne, 20(1), 147-156. 10.1590/S0104-77602014000100018

Croge, C. P., Cuquel, F. L., Biasi, L. A., \& Bona, C. D. (2016). Performance of blackberry cultivars in Cerro Azul - PR. Revista Brasileira de Fruticultura, 38(3): e-141. 10.1590/0100-29452016141

Croge, C. P., Cuquel, F. L., Biasi, L. A., Bona, C. D., \& Pintro, P. T. M. (2019). Agronomic performance of blackberry cultivars in Lapa-PR. Revista Brasileira de Fruticultura, 41(2): e-101. 10.1590/0100-29452019101

Debner, A. R., Hatterman-Valenti, H., \& Takeda, F. (2019). Blackberry propagation limitations when using floricane cuttings. Hortechnology, 29(3), 276-282. 10.21273/HORTTECH04266-18

Dias, P. C., Oliveira, L. S., Xavier, A., \& Wendling, I. (2012a). Estaquia e miniestaquia de espécies florestais lenhosas do Brasil. Pesquisa Florestal Brasileira, 32(72), 453-462. 10.4336/2012.pfb.32.72.453

Dias, P. C., Xavier, A., Oliveira, L. S. de, Paiva, H. N. de, \& Correia, A. C. G. (2012b). Propagação vegetativa de progênies de meios-irmãos de angico vermelho (Anadenathera macrocarpa (Benth) Brenan) por miniestaquia. Revista Árvore, 36(3), 389-399. 10.1590/S0100-67622012000300001

Engel, M. L., Higa, A. R., Alcantara, G. B., Flôres Junior, P. C., \& Soares, I. D. (2017). Enraizamento de miniestacas de diferentes clones de Acacia mearnsii De Wildeman com aplicação de AIB. Revista Espacios, 38(23), 8. Retrieved from https://www.revistaespacios.com/a17v38n23/17382308.html

Ferreira, B. G. A., Zuffellato-Ribas, K. C., Wendling, I., Koehler, H. S., \& Nogueira, A. C. (2010). Miniestaquia de Sapium glandulatum (Vell.) Pax com o uso de ácido indol butírico e ácido naftaleno acético. Ciência Florestal, 20(1), 19-31. 10.5902/198050981758

Ferreira, D. F. (2011). Sisvar: um sistema computacional de análise estatística. Ciência e Agrotecnologia, 35(6), 1039-1042. 10.1590/S141370542011000600001

Ferriani, A. P., Zuffellato-Ribas, K. C., Helm, C. V., Boza, A., Wendling, I., \& Koehler, H. S. (2011). Produção de brotações e enraizamento de miniestacas de Piptocarpha angustifolia. Pesquisa Florestal Brasileira, 31(67), 257-264. https://pfb.cnpf.embrapa.br/pfb/index.php/pfb/article/view/172. 
Hussain, I., Roberto, S. R., Colombo, R. C., Assis, A. M., \& Koyama, R. (2017). Cutting types collected at different seasons on blackberry multiplication. Revista Brasileira de Fruticultura, 39(3), e-939. 10.1590/0100-29452017939

Koyama, R., Assis, A. M., Borges, W. F. S., Yamamoto, L. Y., Colombo, R. C., Zeffa, D. M., Barros, L. G., Barreira, B., Hussain, I., Shahab, M., Ahmed, S., \& Roberto, S. R. (2018). Multiplication of blueberry mini-cuttings in different growth media. Agronomy Science and Biotechnology, 4(1), 28-35. 10.33158/ASB.2018v4i1p28

Menezes, A., Sampaio, P. T. B., \& Blind, A. D. (2018). Propagação de pau-rosa (Aniba Rosaeodora Ducke) por estacas e miniestacas. Nucleus, 15(1), 515521. $10.3738 / 1982.2278 .1829$

Oliveira, T. P. F., Barroso, D. G., Lamônica, K. R., \& Carvalho, G. C. M. W. (2016). Aplicação de AIB e tipo de miniestacas na produção de mudas de Handroanthus heptaphyllus Mattos. Ciência Florestal, 26(1), 313-320. 10.5902/1980509821128

Oliveira, T. P. F., Barroso, D. G., Lamônica, K. R., Carvalho, V. S., \& Oliveira, M. A. (2015). Efeito do ácido indol-3-butírico (AIB) no enraizamento de miniestacas de ipê roxo (Handroanthus heptaphyllus Mattos). Ciência Florestal, 25(4), 1043-1051. 10.5902/1980509820666

Peña, M. L. P., Zanette, F., \& Biasi, L. A. (2015). Época de coleta e ácido indolbutírico no enraizamento de miniestacas de pitangueira. Semina: Ciências Agrárias, 36(5), 3055-3068. 10.5433/1679-0359.2015v36n5p3055-3068

Pereira, A. S., Shitsuka, D. M., Parreira, F. J., \& Shitsuka, R. (2018). Metodologia da pesquisa científica. Ed. UAB/NTE/UFSM.

Schiehl, M., França, T. O., \& Biasi, L. A. (2020). Adequação de protocolo para cultivo in vitro de amoreira-preta (Rubus sp.) 'Xingu'. Journal of Biotechnology and Biodiversity, 8(2), 79-97. 10.20873/jbb.uft.cemaf.v8n2.schiehl

Silva, R. L., Oliveira, M. L., Monte, M. A., \& Xavier, A. (2010). Propagação clonal de guanandi (Calophyllum brasiliense) por miniestaquia. Agronomía Costarricense, 34(1), 99-104. http://www.scielo.sa.cr/scielo.php?script=sci_arttext\&pid=S0377-94242010000100010\&lng=en\&tlng=es

Soler, L. S., \& Biasi, L. A. (2020). Agronomic performance of blackberry cultivars in environmental protection area. Comunicata Scientiae, 11, e3281. $10.14295 /$ cs.v11i0.3281

Vendruscolo, E. P., Campos, L. F. C., \& Seleguini, A. (2018). Soluções de niacina e estacas com diferentes números de gemas para propagação de amorapreta. Nativa, 6(2), 134-138. 10.31413/nativa.v6i2.5054

Vignolo, G. K., Picolotto, L., Gonçalves, M. A., Pereira, I. S., \& Antunes, L. E. C. (2014). Presença de folhas no enraizamento de estacas de amoreira-preta. Ciência Rural, 44(3), 467-472. 10.1590/S0103-84782014000300013

Volk, G. M., Olmstead, J. W., Finn, C. E., \& Janick, J. (2013). The ASHS outstanding fruit cultivar award: a 25-year retrospective. Hortscience, 48(1), 4-12. 10.21273/HORTSCI.48.1.4

Wendling, I., Xavier, A., Gomes, J. M., Pires, I. E., \& Andrade, H. B. (2000). Propagação clonal de híbridos de Eucalyptus spp. por mini-estaquia. Revista Árvore, 24(2), 181-186.

Xavier, A., Andrade, H. B., Oliveira, M. L., \& Wendling, I. (2001). Desempenho do enraizamento de micro-estacas e mini-estacas de clones híbridos de Eucalyptus grandis. Revista Árvore, 25(4), 403-411.

Xavier, A., Santos, G. A., Wendling, I., \& Oliveira, M. L. (2003). Propagação vegetativa de cedro rosa por mini-estaquia. Revista Árvore, 27(2), 139-143. 10.1590/S0100-67622003000200003

Xavier, A., Wendling, I., \& Silva, R. L. (2009). Silvicultura clonal: princípios e técnicas. Ed. UFV. 